\title{
Recombinant Vaccinia PSA Vaccine
}

National Cancer Institute

\section{Source}

National Cancer Institute. Recombinant Vaccinia PSA Vaccine. NCI Thesaurus. Code C2433.

A vaccine consisting of recombinant vaccinia virus encoding prostate specific antigen (PSA). Vaccination with recombinant vaccinia prostate-specific antigen vaccine stimulates the host immune system to mount a cytotoxic T-cell response against tumor cells expressing PSA. 